This document is the Accepted Manuscript version of a Published Work that appeared in final form in Organic Electronics, copyright @ Elsevier after peer review and technical editing by the publisher. To access the final edited and published work see https://doi.org/10.1016/j.orgel.2019.07.002

\title{
Near-infrared absorbing cyanine dyes for all-organic optical
}

\section{upconversion devices}

Rian Aderne ${ }^{1}$, Karen Strassel $^{2,3}$, Sandra Jenatsch $^{4}$, Matthias Diethelm $^{2,5}$, Roland Hany $^{2 *}$, Frank Nüesch ${ }^{2,5}$, Rafael dos Santos Carvalho ${ }^{1}$, Cristiano Legnani ${ }^{6}$, Marco Cremona $^{1^{*}}$

${ }^{1}$ Optoelectronic Molecular Laboratory, Physics Department, Pontifical Catholic University of Rio de Janeiro, PUC-Rio, Rio de Janeiro, RJ, 224543-970, Brazil.

${ }^{2}$ Empa, Swiss Federal Laboratories for Materials Science and Technology, Laboratory for Functional Polymers, CH-8600 Dübendorf, Switzerland.

${ }^{3}$ Institute of Chemical Sciences and Engineering, Ecole Polytechnique Fédérale de Lausanne, EPFL, Station 6, CH-1015 Lausanne, Switzerland.

${ }^{4}$ Fluxim AG, Katharina-Sulzer Platz 2, 8400 Winterthur, Switzerland.

${ }^{5}$ Institute of Materials Science and Engineering, Ecole Polytechnique Fédérale de Lausanne, EPFL, Station 12, CH-1015 Lausanne, Switzerland.

${ }^{6}$ Organic Electronics Laboratory, Physics Department, Federal University of Juiz de Fora, UFJF, Juiz de Fora, MG, 36036-900, Brazil.

This document is the accepted manuscript version of the following article: Aderne, R., Strasse1, K., Jenatsch, S., Diethe1m, M., Hany, R., Nüesch, F., ... Cremona, M. (2019). Near-infrared absorbing cyanine dyes for a11-organic optical upconversion devices. Organic Electronics, 74, 96-102. https://doi.org/10.1016/j.orge1.2019.07.002

This manuscript version is made available under the CC-BY-NC-ND 4.0 license http://creativecommons.org/1icenses/by-nc-nd/4.0/ 
*Correspondence should be addressed to:

Marco Cremona, Phone +55 213527 1268, E-mail cremona@fis.puc-rio.br

Roland Hany, Phone +41 58765 4084, E-mail roland.hany@empa.ch

Keywords: Upconverter; Photodetector; Near-Infrared; Cyanine Dye; Organic Light-Emitting Device

\section{ABSTRACT}

The development of near-infrared (NIR) photodetection technologies is driven by emerging applications such as medical imaging or optical sensors for electronic displays and machine vision. An all-organic upconverter (OUD) is a device that converts incident NIR light directly into visible light and consists of a monolithic stack of a NIR organic photodetector (OPD) and a visible organic light-emitting diode (OLED). We present OUDs that consist of NIR heptamethine cyanine dyes / $\mathrm{C}_{60}$ fullerene OPDs and a fluorescent tris(8-

hydroxyquinolinato)aluminium ( $\left.\mathrm{Alq}_{3}\right)$ OLED. The device metrics of performance are a high external quantum efficiency (EQE) of $43 \%$ of the OPD part and an OUD luminance turn-on at low bias voltages of $2 \mathrm{~V}$. The dynamic response of the photocurrent and luminance is linear over a NIR light range corresponding to $26 \mathrm{~dB}$. These OUDs upconvert NIR light at $830 \mathrm{~nm}$ to green light with a photon-to-photon conversion efficiency of $0.61 \%$, close to the expected maximum.

\section{Introduction}

Detection and imaging light in the near-infrared (NIR) wavelength region underpins modern science and technology, including communication, process control, medical imaging, 
passive night vision and machine vision systems [1-5]. NIR imaging is currently realized by using an InGaAs photodetector (PD) array interconnected with a silicon readout circuit. However, the assembly between two separate chips is complex and intermediate electronics for data processing as well as a display for visualization are required, resulting in high production costs [6].

As an alternative approach, upconversion devices have been presented that directly convert NIR into visible light. Upconversion devices consist of an NIR PD and a visibleemitting component, connected in series [6]. When NIR light is absorbed by the PD, electronhole pairs are formed. Under an appropriate bias, charges are driven in the light-emitting component where they recombine leading to visible light emission. The outcome is an NIRto-visible upconverted image that can be captured using a conventional camera.

Recently, upconversion devices were presented by combining inorganic compound semiconductor [7,8], colloidal quantum dot [9] and perovskite [10] PDs with an organic lightemitting diode (OLED). OLEDs are attractive for the fabrication of upconversion devices because of their ease of fabrication, high efficiency and adjustability of the emitted visible colour [11].

All-organic upconverters (OUDs) consist of a series-connected organic NIR photodetector (OPD) with an organic light-emitting diode (OLED) [12-14]. Most reported OUDs were fabricated by thermal evaporation and used phosphorescent OLEDs in combination with phthalocyanines as NIR sensitizers [15-19]. The library of tested NIR sensitive organic compounds is relatively small because not many molecules and polymers with selective absorption in the NIR are known [20]. For OUD applications, selective NIR sensitizers are important because visible light absorption of broadband OPDs [21,22] results in a nonselective NIR response of the device. In addition, NIR selective absorption is crucial for OUDs that contain a 
thick metallic top electrode. In such a case, the incident NIR light and out-coupled visible light are measured from the same side and a broadband OPD can re-absorb a fraction of the light emitted from the OLED [10], compromising the device efficiency.

For the future development of large-area, flexible and low-cost OUDs it is also advantageous to find solution-processable NIR OPDs. Recently [23], we demonstrated a solutionprocessed squaraine dye-based OPD with selective NIR absorption and a peak sensitivity at $980 \mathrm{~nm}$. When combined with a transparent OLED and an optimized semi-transparent metal top electrode, visibly transparent OUDs were achieved with an average visible transmittance of $65 \%$ and a peak transmittance of $80 \%$ at $620 \mathrm{~nm}$.

Here, we report on the use of selective NIR-absorbing cyanine dyes for the fabrication of OUDs. Cyanine dyes have a number of interesting property characteristics such as ease of synthesis and purification, tunable absorption in a narrow wavelength range, high light extinction coefficients and good film formation properties from organic solvents. Cyanine dyes have initially been used as spectral sensitizers for silver halide emulsion photography [24], and have recently attracted interest for optoelectronic device applications such as light-emitting electrochemical cells [25], solar cells [26-32] and NIR photodetectors $[20,33]$.

We compared a commercial (Cy7-P) with an in-house synthesized (Cy7-T) cyanine dye. Both dyes are heptamethine cyanines but they have a different chemical structure and, therefore, have different absorbance maxima and redox energy level. Also, they are accompanied by a small ( $\mathrm{PF}_{6}{ }^{-}$in $\left.\mathrm{Cy} 7-\mathrm{P}\right)$ or a large (trisphate in Cy7-T) charge-compensating counter anion. In a first step we demonstrate that efficient $\mathrm{Cy} 7 / \mathrm{C}_{60}$ bilayer OPDs can be fabricated in the inverted device architecture (substrate $/ \mathrm{TiO}_{2} / \mathrm{C}_{60} / \mathrm{Cy} 7 / \mathrm{MoO}_{3} / \mathrm{Ag}$ ). By combining these OPDs with a fluorescent $\mathrm{Alq}_{3}$-based OLED, we then demonstrate OUDs that upconvert light 
at $830 \mathrm{~nm}$ to green light with an efficiency close to the expected maximum and with good performance in terms of a low dark current, a low dark luminance value and a highly linear optical response.

\section{Experimental section}

The cyanine dye 3-butyl-2-(2-[3-[2-(3-butyl-1,1-dimethyl-1,3-dihydro-benzo[e]indol-2ylidene)-ethylidene]-2-chloro-cyclohex-1-enyl]-vinyl)-1,1-dimethyl-1H-benzo[e]indolium hexafluorophosphate (Cy7-P) was purchased from FEW Chemicals, 2-[2-[2-chloro-3-[2-(1ethyl-1,3-dihydro-3,3-dimethyl-2H-indol-2-ylidene)ethylidene]-1-cyclohexen-1-yl]ethenyl]-1ethyl-3,3-dimethyl-3H-indolium trisphate(OC-6-11- $\Delta)$-tris[3,4,5,6-tetrachloro-1,2benzenediolato(2-)- $\mathrm{k} \mathrm{O}^{1}, \mathrm{k} \mathrm{O}^{2}$ ]phosphate(1-) (Су7-T) was synthesized as described in ref [26]. $\mathrm{C}_{60}, \mathrm{MoO}_{3}$, LiF, tris(8-hydroxyquinolinato)aluminium $\left(\mathrm{Alq}_{3}\right)$ and $\mathrm{N}, \mathrm{N}^{\prime}$-bis(naphthalen-2-yl)$\mathrm{N}, \mathrm{N}^{\prime}$-bis(phenyl)-benzidine ( $\beta$-NPB) were purchased from Lumtec.

Devices were fabricated in a glove box under $\mathrm{N}_{2}$ atmosphere $\left(\mathrm{H}_{2} \mathrm{O}<1 \mathrm{ppm}, \mathrm{O}_{2}<15 \mathrm{ppm}\right)$. $\mathrm{TiO}_{2}$ films were prepared on cleaned ITO glass substrates (resistivity $\sim 15$ Ohms square ${ }^{-1}$ ) via a sol-gel process using titanium iso-propoxide as precursor [23]. Before deposition of the active layers, $\mathrm{TiO}_{2}$ coated substrates were heated for $10 \mathrm{~min}$ at $120^{\circ} \mathrm{C}$ inside the glove box. Photodetectors had the architecture ITO/TiO $2(35 \mathrm{~nm}) / \mathrm{C}_{60}(30 \mathrm{~nm}) / \mathrm{Cy} 7-\mathrm{T}, \mathrm{P}(15 \mathrm{~nm}) / \mathrm{MoO}_{3}$ $(20 \mathrm{~nm}) / \mathrm{Ag}(50 \mathrm{~nm})$ and upconverters the structure ITO/TiO $2(35 \mathrm{~nm}) / \mathrm{C}_{60}(30 \mathrm{~nm}) / \mathrm{Cy} 7-\mathrm{T}, \mathrm{P}$ $(15 \mathrm{~nm}) / \mathrm{MoO}_{3}(20 \mathrm{~nm}) / \beta-N P B(20 \mathrm{~nm}) / \mathrm{Alq}_{3}(50 \mathrm{~nm}) / \mathrm{LiF}(0.2 \mathrm{~nm}) / \mathrm{Al}(100 \mathrm{~nm})$. Cy7-T and Cy7-P were dissolved $\left(4 \mathrm{mg} \mathrm{ml}^{-1}\right)$ in acetonitrile and filtered $(0.45 \mu \mathrm{m}$ PTFE) solutions were spin coated at $4000 \mathrm{rpm}$ for $60 \mathrm{sec}$. Other layers were deposited by thermal evaporation $(<5$ $x 10^{-6}$ mbar) with an evaporation rate of $0.03 \mathrm{~nm} \mathrm{~s}^{-1}$ for $\mathrm{C}_{60}, \mathrm{MoO}_{3}, \beta-\mathrm{NPB}, \mathrm{Alq}_{3}$ and LiF. Ag 
and Al were evaporated through a shadow mask to define devices with an active area of 3.1 $\mathrm{mm}^{2}$.

Absorbance spectra were measured using a Perkin Elmer Lambda 950 spectrophotometer. Dye film thicknesses were determined with a profilometer Ambios XP1. J-V characteristics were measured using $100 \mathrm{~mW} \mathrm{~cm}^{-2}$ simulated AM1.5G solar irradiation on a calibrated solar simulator from Spectra-Nova. External quantum efficiency (EQE) of the NIR charge generation layer was measured on a commercial setup (SpeQuest, ReRa solutions BV). The monochromatic light was chopped at $85 \mathrm{~Hz}$ during the measurement without additional bias light. Optionally, a voltage bias was applied during spectral response measurements.

Upconverters were characterized outside the glove box in a $\mathrm{N}_{2}$-filled air-tight box covered with a glass window. J-V-L characteristics were measured with a Keithley 2400 and a Konica Minolta luminance meter LS-110 equipped with a close-up lens No.110. As NIR light source we used an Edmund Optics $830 \mathrm{~nm}$ CW circular beam diode laser with a power density of $56.6 \mathrm{~mW} \mathrm{~cm}^{-2}$. The laser was placed $\sim 10 \mathrm{~cm}$ away from the device under an angle of $\sim 40^{\circ}$. Neutral density filters from Edmund Optics were used to attenuate the laser intensity. The NIR light irradiated the sample through the glass/ITO side and the visible back reflected light was measured from the same side.

\section{Results and discussion}


(a)
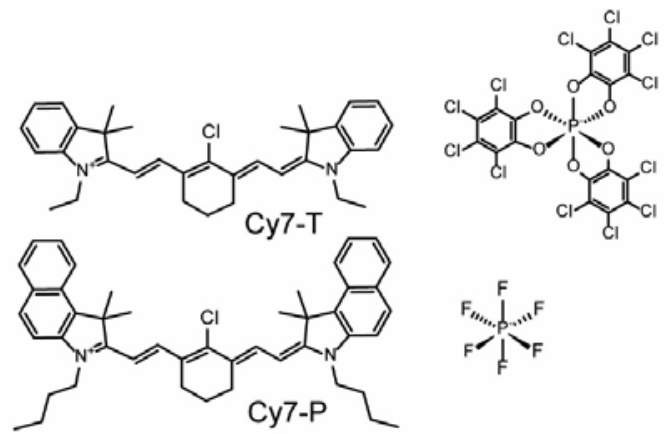

(b)

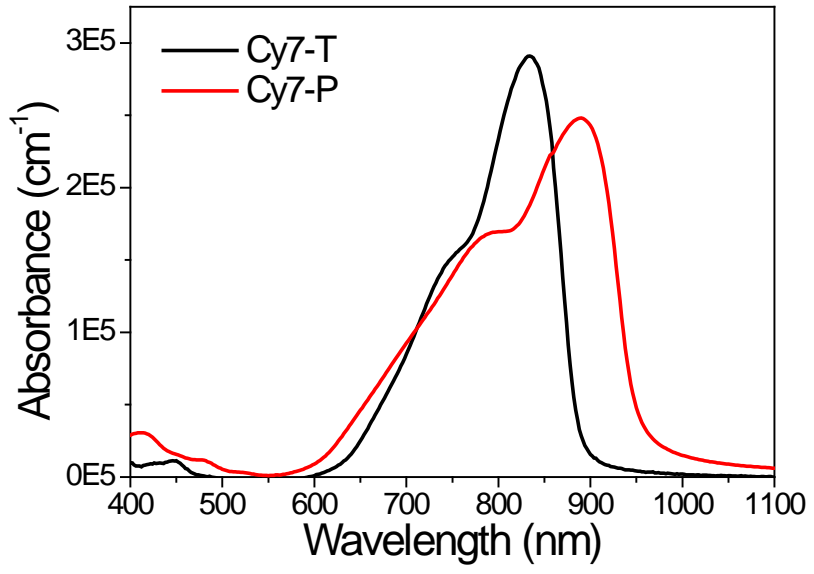

Fig. 1 (a) Chemical structures of the cyanine dyes with the counter anions trisphate (Cy7-T) and hexafluorophosphate (Cy7-P). (b) Film absorbance spectra of the dyes.

Fig. 1a shows the chemical structure of the two heptamethine cyanine dyes. The corresponding film absorbance spectra are shown in Fig. 1b. The maximum absorption of Cy7-T is at $833 \mathrm{~nm}$ and of Cy7-P at $890 \mathrm{~nm}$. The absorptions in the visible ( $450 \mathrm{~nm}-670 \mathrm{~nm}$ [23]) are small, demonstrating that both dyes are selective NIR absorbers. 
(a)

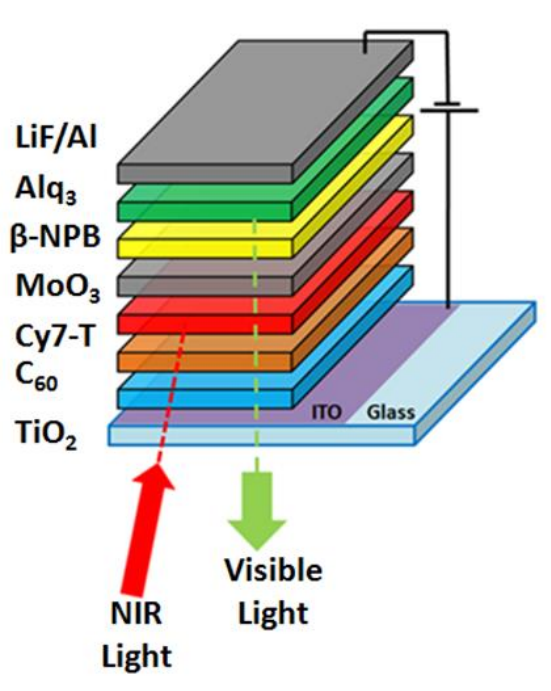

(b) ITO $\mathrm{TiO}_{2} \mathrm{C}_{60}$ Cy7-T $\mathrm{MoO}_{3} \beta-\mathrm{NPB} \quad \mathrm{Alq}_{3} \mathrm{LiF} / \mathrm{Al}$
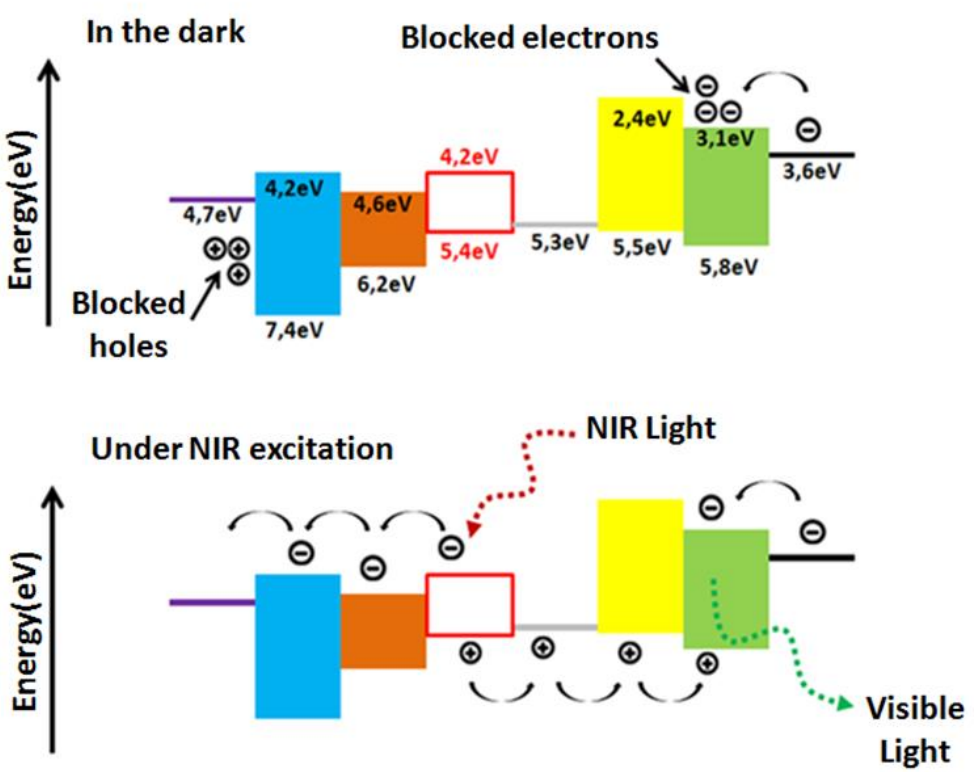

Fig. 2 (a) Schematics of the device architecture. (b) Scheme of device operation in the absence and presence of NIR light.

The OUD consisted of a stack of an $\left(\mathrm{ITO} / \mathrm{TiO}_{2} / \mathrm{C}_{60} / \mathrm{Cy} 7 / \mathrm{MoO}_{3}\right)$ OPD with an ( $\beta$ $\mathrm{NPB} / \mathrm{Alq}_{3} / \mathrm{LiF} / \mathrm{Al}$ ) OLED and the device operation mechanism can be explained with help of Fig. 2. Both in the absence and presence of NIR light, a forward bias is applied. In the dark, electrons and holes are blocked at the $\beta-\mathrm{NPB} / \mathrm{Alq}_{3}$ and $\mathrm{ITO} / \mathrm{TiO}_{2}$ interfaces, respectively. Thus, in the dark, the flowing current is low and consequently no light is emitted. In the presence of NIR light, electron-hole pairs are formed at the $\mathrm{C}_{60} / \mathrm{Cy} 7$ interface. Subsequently, electrons will be transported via the $\mathrm{TiO}_{2}$ layer to the anode while the holes are driven into the OLED where they recombine under visible light emission with electrons injected from the cathode. 

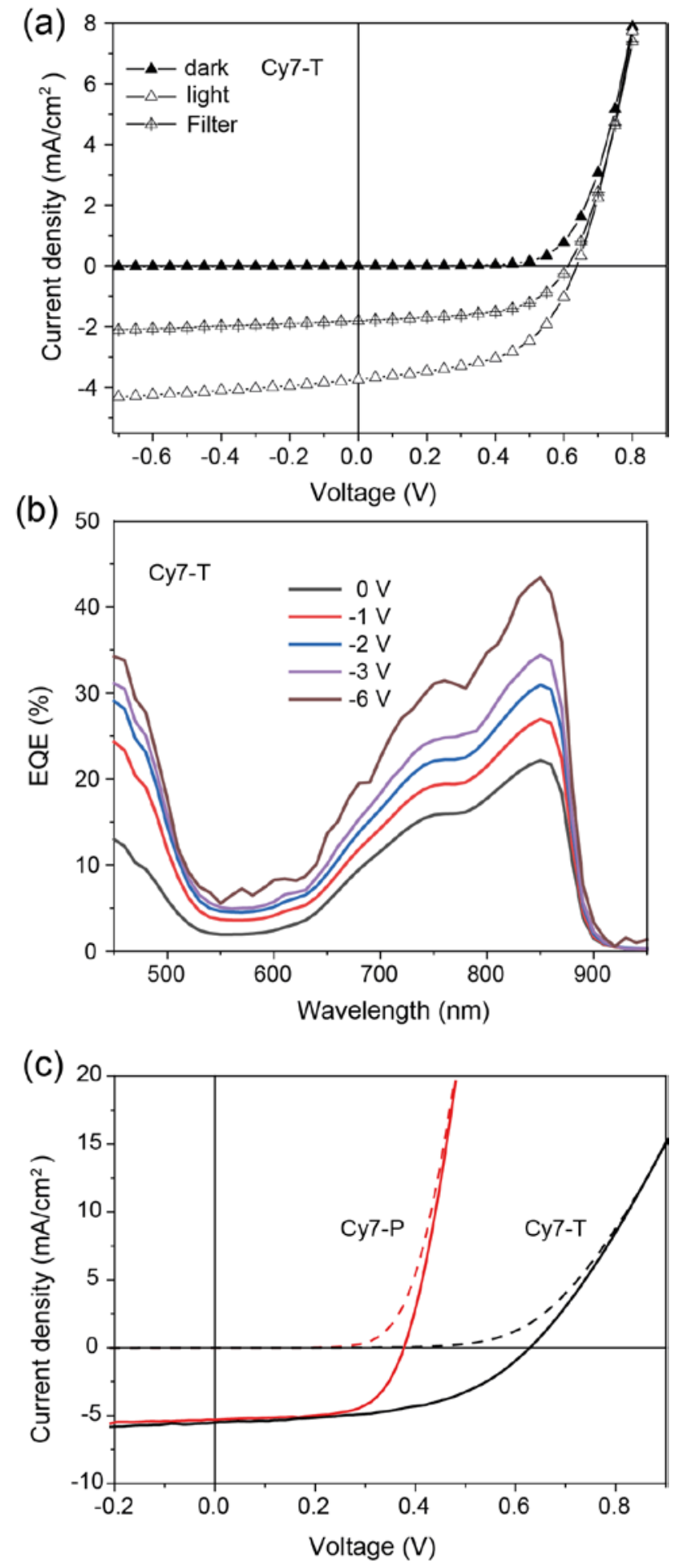

Fig. 3 (a) J-V curves of an $\mathrm{ITO} / \mathrm{TiO}_{2} / \mathrm{C}_{60} / \mathrm{Cy} 7-\mathrm{T} / \mathrm{MoO}_{3} / \mathrm{Ag}$ photodetector measured in the dark, when irradiated with white light, and when using white light and an optical high-band pass filter. (b) EQEs as function of voltage bias. (c) Comparison between typical J-V scans of inverted photodetectors when using Cy7-P or Cy7-T as donor materials. 
There is no agreed protocol how the performance of OUDs has to be rated, but it is clear that an efficient device should have a low dark current, and consequently a low luminance in the OFF state. Because the dark current increases when the bias voltage is increased, the current and luminance ON/OFF ratios (for a given NIR light intensity) pass through a maximum and, to minimize the power consumption, the corresponding voltage should be as small as possible. A low dark current will be reflected in high ON/OFF ratios for the current and luminance, although the actual values are not clear performance indicators because they depend on the NIR light intensity and wavelength.

An important performance metrics is the fraction of incident NIR photons that are converted into visible emitted photons, the photon-to-photon conversion efficiency (P2PCE). For a given OLED, a high P2PCE value requires an efficient OPD. Fig. 3a shows the J-V curves of an ITO/ $\mathrm{TiO}_{2} / \mathrm{C}_{60} / \mathrm{Cy} 7-\mathrm{T} / \mathrm{MoO}_{3} / \mathrm{Ag}$ OPD. In earlier work we used chlorobenzene as the solvent to fabricate $\mathrm{C}_{60} / \mathrm{Cy} 7-\mathrm{T}$ heterojunctions [33]. This required an extra photopolymerization step of the fullerene layer before spin coating because $C_{60}$ is soluble in chlorobenzene. Here we used acetonitrile to dissolve the cyanine and because in this solvent $C_{60}$ is insoluble, no prior photo-polymerization was necessary. Cells were measured in the dark, were irradiated with full white light $\left(100 \mathrm{~mW} \mathrm{~cm}^{-2}\right)$ and white light including a filter that blocks light below $700 \mathrm{~nm}$. It can be seen that $\mathrm{C}_{60}$ and $\mathrm{Cy} 7-\mathrm{T}$ contribute approximately equally to the photocurrent. EQE spectra for this device are shown in Fig. 3b. At short circuit ( $0 \mathrm{~V}$ applied), the EQE in the NIR is $22 \%$. EQEs increased almost linearly with reverse bias and reached a value of $43 \%$ at $-6 \mathrm{~V}$.

Fig. 3c shows a comparison between J-V scans of inverted OPDs when using Cy7-P and Cy7-T. For Cy7-P, average performance values were $\mathrm{V}_{\mathrm{oc}}=0.37 \mathrm{~V}$ for the open-circuit 
voltage, $\mathrm{J}_{\mathrm{sc}}=5.0 \mathrm{~mA} \mathrm{~cm}^{-2}$ for the short-circuit current and $\mathrm{FF}=64.1 \%$ for the fill factor, resulting in a power conversion efficiency of $\eta=1.2 \%$. For Cy7-T, $\mathrm{V}_{\mathrm{oc}}=0.62 \mathrm{~V}, \mathrm{~J}_{\mathrm{sc}}=4.4 \mathrm{~mA} \mathrm{~cm}{ }^{-2}$, $\mathrm{FF}=48.5 \%$ were measured, and $\eta$ was $1.3 \% . \mathrm{V}_{\text {oc }}$ values for Cy $7-\mathrm{T}$ cells were significantly larger than when using Cy7-P, in agreement with results observed for regular cells with the structure: ITO/ $\mathrm{MoO}_{3} / \mathrm{Cy} 7 / \mathrm{C}_{60} / \mathrm{Alq}_{3} / \mathrm{Ag}[26] . \mathrm{V}_{\text {oc }}$ correlates with the energy levels of the HOMO of the donor (Cy7) and the LUMO of the acceptor $\left(C_{60}\right)$ [34]. Redox levels measured by cyclic voltammetry (CV) were for Cy7-T HOMO = -5.37 eV, LUMO = -4.2 eV [26], and for Cy7$\mathrm{P}$ HOMO $=-5.28 \mathrm{eV}, \mathrm{LUMO}=-3.79 \mathrm{eV}$ [27]. The HOMO energy level of CY7-T is $\sim 0.1 \mathrm{eV}$ higher than that of Cy7-P, in agreement with the observed $V_{\text {oc }}$ difference. We note, however, that the $\mathrm{CV}$ redox potentials do not necessarily reflect the energetic situation in the solid film, because in solution the anions are dissociated from the cyanine cations. From ultraviolet photoelectron spectroscopy (UPS) data on cyanine films it has been demonstrated that changing the anions alters the frontier orbital energies [20,32]. Therefore, for a given cyanine chromophore, the $\mathrm{V}_{\text {oc }}$ depends strongly on the anion.

Fig. 4 shows the electrical and optical characteristics for both OUDs in the dark and under NIR illumination $\left(56.6 \mathrm{~mW} \mathrm{~cm}^{-2}\right)$ at $830 \mathrm{~nm}$. For Cy7-T the device was completely blocking below $1.75 \mathrm{~V}$ and the dark current was below $2 \times 10^{-5} \mathrm{~mA} \mathrm{~cm}^{-2}$ (Fig. 4a). The dark current increased to a value of $0.47 \mathrm{~mA} \mathrm{~cm}^{-2}$ at $10 \mathrm{~V}$, accompanied with a dark currentinduced luminance onset $\left(1 \mathrm{~cd} \mathrm{~m}^{-2}\right.$ at $\left.8 \mathrm{~V}\right)$ and maximum luminance of $11.2 \mathrm{~cd} \mathrm{~m}^{-2}$ at $10 \mathrm{~V}$ (Fig. 4c). For Cy7-P, dark currents were slightly higher (0.6 $\mathrm{mA} \mathrm{cm}^{-2}$ at $10 \mathrm{~V}$, Fig. 4b), the dark current-induced luminance onset was at $7.5 \mathrm{~V}$ and the maximum luminance in the absence of NIR light was $14 \mathrm{~cd} \mathrm{~m}^{-2}$ at $10 \mathrm{~V}$ (Fig. 4d).

In the ON state, the current for both devices increased sharply at $1.75 \mathrm{~V}$ and the ON/OFF ratio passed a maximum of 2383 for Cy7-T and of 1407 for Cy7-P, both at $4.5 \mathrm{~V}$. The 
light-induced current levelled off beyond $\sim 6 \mathrm{~V}$ at $12.5 \mathrm{~mA} \mathrm{~cm} \mathrm{~cm}^{-2}$ for Cy7-T. Because Cy7-P absorbs less light at $830 \mathrm{~nm}$ than Cy7-T (Fig. 1b), also the light-induced current $\left(9.5 \mathrm{~mA} \mathrm{~cm}^{-2}\right.$ beyond $\sim 6 \mathrm{~V}$ ) was smaller. Following the current trend, the luminance in the presence of NIR light levelled off at $670 \mathrm{~cd} \mathrm{~m}^{-2}$ for Cy7-T and the maximum light/dark ratio of the luminance was 4211 at $5 \mathrm{~V}$ (Fig. 4c). For Cy7-P, the maximum luminance was $380 \mathrm{~cd} \mathrm{~m}^{-2}$ and the maximum light/dark ratio of the luminance was 3056 at $5 \mathrm{~V}$ (Fig. 4d). The onset voltages for the current and luminance agree with those of a standard (ITO/ $\left.\mathrm{MoO}_{3} / \mathrm{NPB} / \mathrm{Alq} \mathrm{q}_{3} / \mathrm{LiF} / \mathrm{Al}\right)$ OLED [35], demonstrating the low resistive hole transfer across the $\mathrm{Cy} 7-\mathrm{MoO}_{3}$ interface for both cyanine dyes, despite their different HOMO energy levels.
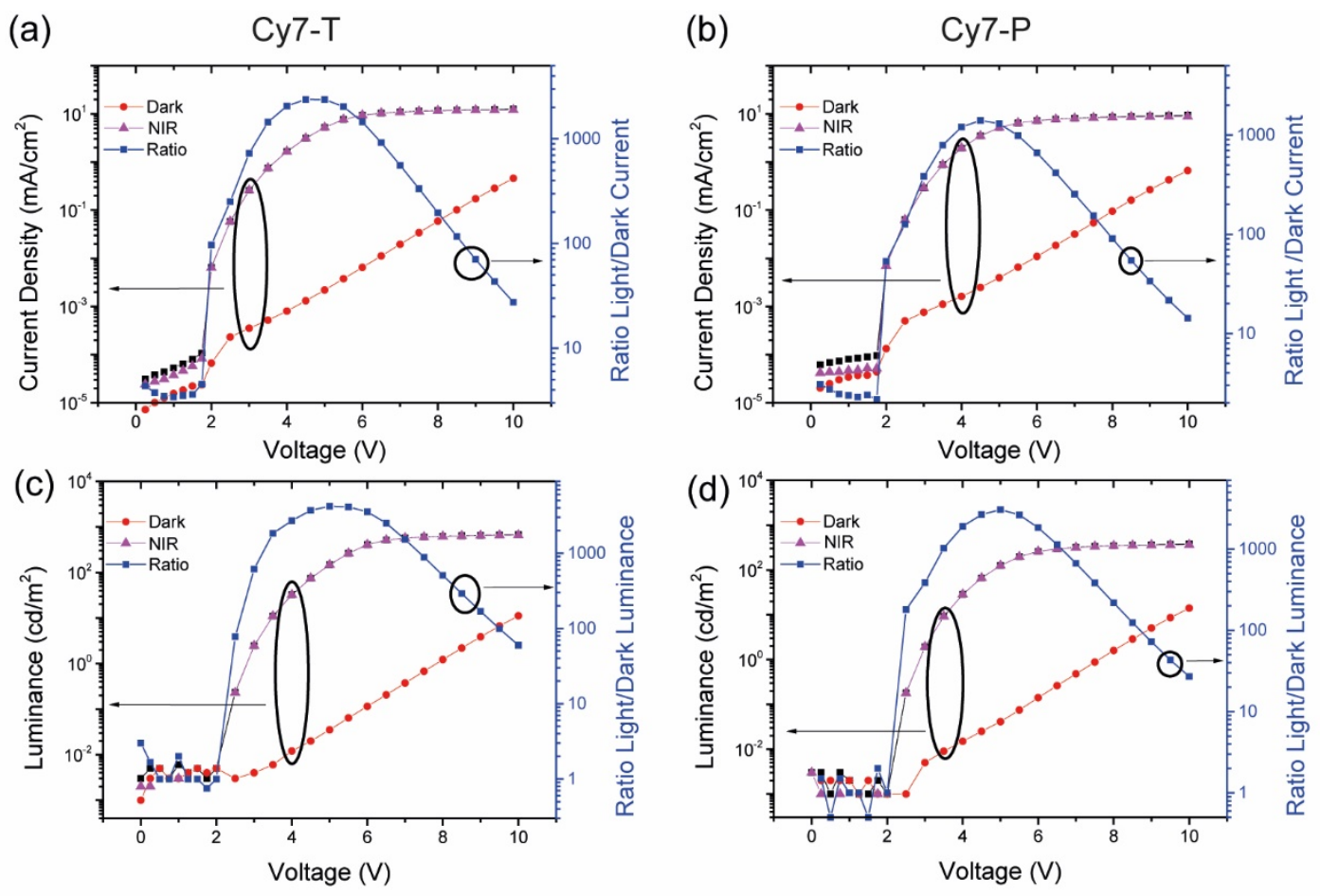

Fig. 4 Current-voltage and luminance-voltage trends of upconverters using Cy7-T and Cy7-P. (a), (b) current and (c), (d) luminance in the dark and under NIR $\left(830 \mathrm{~nm}, 56.6 \mathrm{~mW} \mathrm{~cm}{ }^{-2}\right)$ irradiation. 
For the calculation of the P2PCE, the number of emitted visible photons was determined from the electroluminescence spectrum and the radiance, which was calculated from the measured luminance using the photopic response function. It was divided by the number of incident NIR photons, calculated from the laser intensity. The full calculation is described in the supporting information of ref. [23]. In order to consider only the NIR light-induced visible light output, the dark current-induced luminance was subtracted from the total luminance. Fig. 5a shows the P2PCEs as a function of the applied voltage. For both devices the P2PCE increased steeply beyond $\sim 4 \mathrm{~V}$ and the maximum values at $10 \mathrm{~V}$ were $0.61 \%$ for Cy7-T and $0.34 \%$ for Cy7-P. The P2PCE can be estimated from the individual EQEs of the OPD and the OLED. For Al/LiF/Alq 3 /NPB OLEDs an efficiency of around $1.3 \%$ was reported [36]. Together with the measured EQE of the OPD ( $\sim 0 \%$ at an electric field of $10 \mathrm{~V} /$ active layer thickness), an achievable overall OUD efficiency for our materials combination of $\sim 0.5 \%$ can be expected, in good agreement with the observed P2PCEs.

(a)

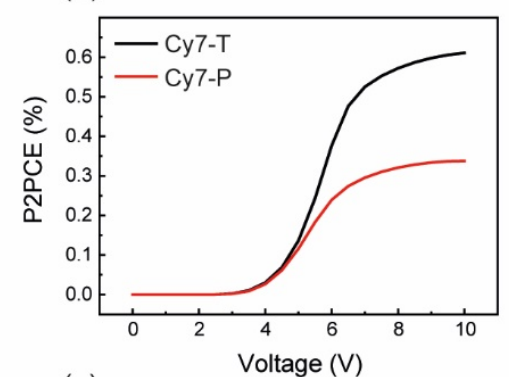

(c)

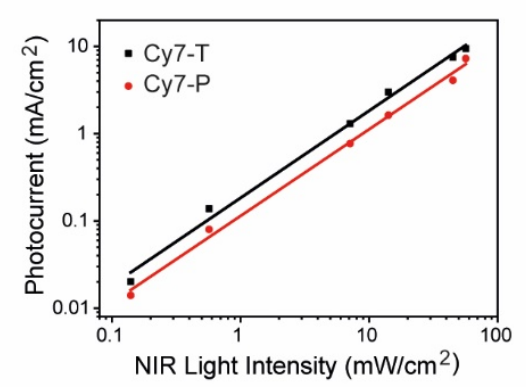

(b)

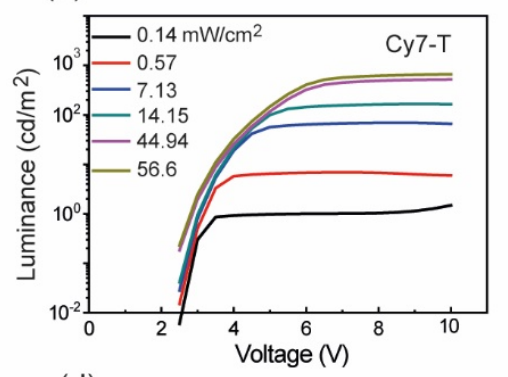

(d)

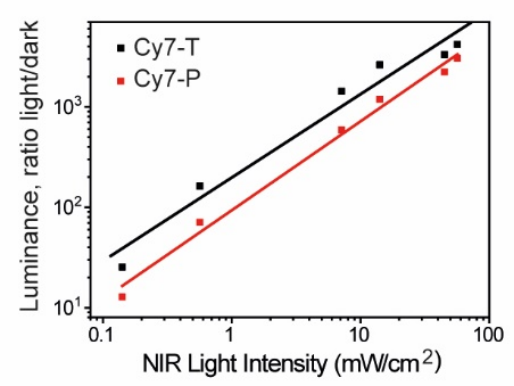


Fig. 5 (a) NIR photon to visible photon conversion efficiencies for Cy7-T and Cy7-P upconverters as function of the applied voltage. The NIR light intensity was $56.6 \mathrm{~mW} \mathrm{~cm}^{-2}$. (b) Luminance trends for different NIR light intensities, in each case the dark current induced luminance was subtracted. (c) and (d) Photocurrent and luminance as function of the NIR light intensity, analysed at an applied voltage of $6 \mathrm{~V}$.

As we show for the OUD incorporating Cy7-T the NIR light-induced luminance output at a given NIR irradiation intensity saturates at a certain voltage (Fig. 5b). This clearly supports an upconversion mechanism where the luminance is proportional to the current output of the inverted NIR OPD connected in series to the OLED device. At a positive voltage the OPD operates in reverse bias condition, and for high enough applied positive bias the saturation current is limited by the rate of generated carriers, which is proportional to the rate of absorbed NIR photons and only weakly depends on the applied electric field. Another interesting feature seen in Fig. $5 \mathrm{~b}$ is that the luminance onset at $2 \mathrm{~V}$ is independent of the NIR irradiation intensity meaning that the hole and electron currents stemming from the OPD are not limited by interfacial barriers. The onset voltage then is determined by the injection of holes and electrons into the $\mathrm{Alq}_{3}$ emitter layer. We note that the voltage regime where the luminance starts to saturate depends on the NIR light intensity and attribute this characteristic to current limitation in the organic photovoltaic device. It was shown that unbalanced electron and hole mobilities in bilayer photovoltaic devices leads to space charge in the low mobility component [37]. In the cyanine dye/ $\mathrm{C}_{60}$ OPD discussed in this work we indeed expect such imbalance because the hole mobility of cyanines are known to be rather low $\left(\sim 5-10 \times 10^{-6} \mathrm{~cm}^{2} \mathrm{~V}^{-1} \mathrm{~s}^{-1}[38,39]\right.$. Since the space charge density increases with the current density produced by the NIR photovoltaic cell, space charge limitation will be more pro- 
nounced for the higher NIR irradiation intensities, which corroborates the higher voltage needed to achieve saturation of the hole current and hence the luminance.

The linearity of the OUD response was addressed by measuring the photocurrent (Fig. 5 c) and luminance (Fig. 5d) for different NIR light intensities. We applied NIR light intensities ranging from 0.14 to $56.6 \mathrm{~mW} \mathrm{~cm}^{-2}$, corresponding to a range of $26 \mathrm{~dB}$, and measured a linear response of the photocurrent and luminance at $6 \mathrm{~V}$. This demonstrates that under these conditions all charge carriers generated by the NIR photovoltaic device are injected into the OLED, which itself has a linear relationship between current-density and luminance. Importantly, a linear behaviour is ideal for a direct imaging device based on such NIR upconverters. Even for the smallest NIR light intensity the luminance contrast for Cy7-T was 25 , demonstrating the small dark current induced luminance level.

The NIR-to-visible upconversion capability of the OUD is finally shown in Fig. 6. Without NIR light the device appears dark, while in the presence of NIR light the green emission is clearly visible. This demonstrates that a high luminance contrast is an important performance metrics, implying a low dark current when the device is in the OFF state.

(a)

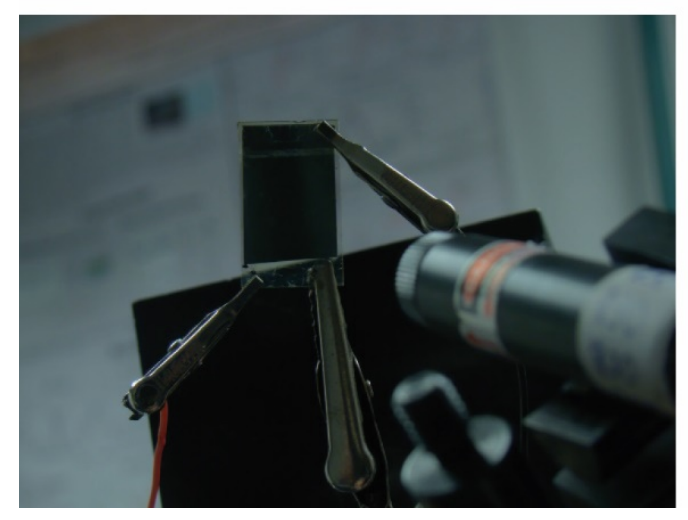

(b)

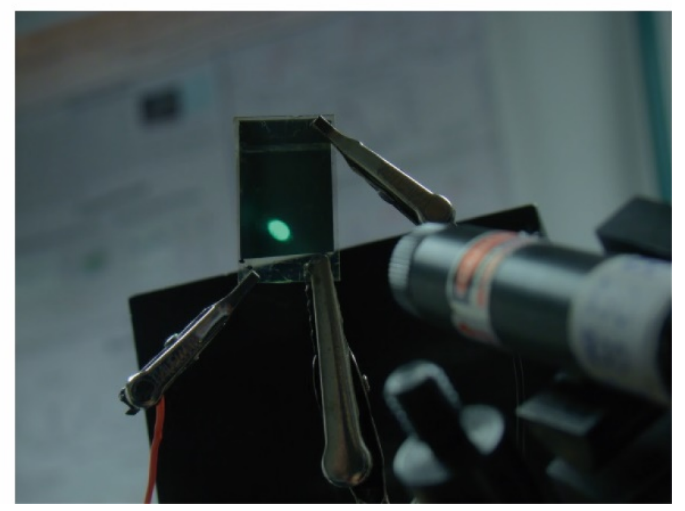


Fig. 6 Images of cyanine OUDs without (a) and with (b) NIR light at $830 \mathrm{~nm}\left(56.6 \mathrm{~mW} \mathrm{~cm}{ }^{-2}\right)$. In both cases, a forward bias of $10 \mathrm{~V}$ was applied.

\section{Conclusions}

By combining NIR cyanine-based OPDs with a fluorescent OLED, we demonstrated OUDs with a conversion efficiency of NIR (at $830 \mathrm{~nm}$ ) to visible green light close to the expected maximum. The sharp rise of the luminance after device turn-on indicates the efficient photocarrier injection from the OPD to the OLED. Consequently, these OUDs can be run at a low voltage bias. A merit of NIR cyanine dyes is their relatively small absorption in the visible, which suppresses non-selective device response as well as prevents re-absorption of the emitted visible light by the OPD. Recent reports of cyanine dyes with photoresponse out to $1600 \mathrm{~nm}[20]$ and a NIR narrow-band cyanine OPD [40] suggest that this dye class is suitable to address important remaining challenges with OUDs in the fields of NIR light sensing and imaging beyond the silicon band edge as well as narrow-band NIR light sensing [4].

\section{Acknowledgements}

Financial support from the Swiss National Science Foundation (grant number IZRJZ2_164179/1), FAPERJ/CNPq, INCT-INEO and CAPES is acknowledged.

\section{References}

[1] F.P.G. de Arquer, A. Armin, P. Meredith, E.H. Sargent, Solution-processed semiconductors for next-generation photodetectors, Nat. Rev. Mater. 2 (2017) 16100. 
[2] A. Armin, R.D. Jansen-van Vuuren, N. Kopidakis, P.L. Burn, P. Meredith, Narrowband light detection via internal quantum efficiency manipulation of organic photodiodes, Nat. Commun. 6 (2015) 6343.

[3] B. Siegmund, A. Mischok, J. Benduhn, O. Zeika, S. Ullbrich, F. Nehm, M. Böhm, D. Spoltore, H. Fröb, C. Körner, K. Leo, K. Vandewal, Organic narrowband near-infrared photodetectors based on intermolecular charge-transfer absorption, Nat. Commun. 8 (2017) 15421.

[4] X. Liu, Y. Lin, Y. Liao, J. Wu, Y. Zheng, Recent advances in organic near-infrared photodiodes, J. Mater. Chem. C 6 (2018) 3499-3513.

[5] R.D. Jansen-van Vuuren, A. Armin, A.K. Pandey, P.L. Burn, P. Meredith, Organic photodiodes: the future of full color detection and image sensing, Adv. Mater. 28 (2016) 4766-4802.

[6] J. Tao, J. Chen, D. Ban, M.G. Helander, Z.H. Lu, Optical up-conversion devices for infrared detection and imaging, Sci. Adv. Mater. 4 (2012) 266-281.

[7] X. Chu, M. Guan, L. Niu, Y. Zeng, Y. Li, Y. Zhang, Z. Zhu, B. Wang, Fast responsive and highly efficient optical upconverter based on phosphorescent OLED, ACS Appl. Mater. Interfaces 6 (2014) 19011-19016.

[8] J. Chen, J. Tao, D. Ban, M.G. Helander, Z. Wang, J. Qiu, Z. Lu, Hybrid organic/inorganic optical up-converter for pixel-less near-infrared imaging, Adv. Mater. 24 (2012) 31383142.

[9] D.Y. Kim, K.R. Choudhury, J.W. Lee, D.W. Song, G. Sarasqueta, F. So, PbSe nanocrystal-based infrared-to-visible up-conversion device, Nano Lett. 11 (2011) 2109-2113. 
[10] B.H. Yu, Y. Cheng, M. Li, S.-W. Tsang, F. So, Sub-band gap turn-on near-infrared-tovisible up-conversion device enabled by an organic-inorganic hybrid perovskite photovoltaic absorber, ACS Appl. Mater. Interfaces 10 (2018) 15920-15925.

[11] H. Tachibana, N. Aizawa, Y. Hidaka, T. Yasuda, Tunable full-color electroluminescence from all-organic optical upconversion devices by near-infrared sensing, ACS Photonics 4 (2017) 223-227.

[12] M.C. Melquíades, R. Aderne, A. Cuin, W.G. Quirino, M. Cremona, C. Legnani, Investigation of tin(II)2,3-naphtalocyanine molecule used as near-infrared sensitive layer in organic up-conversion devices, Opt. Mater. 69 (2017) 54-60.

[13] D. Yang, X. Zhou, D. Ma, A. Vadim, T. Ahamad, S.M. Alshehri, Near infrared to visible light organic up-conversion devices with photon-to-photon conversion efficiency approaching 30\%, Mater. Horizon 5 (2018) 874-882.

[14] Q. Song, T. Lin, Z. Su, B. Chu, H. Yang, W. Li, C.-S. Lee, Organic upconversion display with an over $100 \%$ photon-to-photon upconversion efficiency and a simple pixelless device structure, J. Phys. Chem. Lett. 9 (2018) 6818-6824.

[15] D.Y. Kim, T.-H. Lai, J.W. Lee, J.R. Manders, F. So, Multi-spectral imaging with infrared sensitive organic light emitting diode, Sci. Rep. 4 (2014) 5946.

[16] D.Y. Kim, D.W. Song, N. Chopra, P. De Somer, F. So, Organic infrared upconversion device, Adv. Mater. 22 (2010) 2260-2263.

[17] C.-H. Yuan, C.-C. Lee, C.-F. Liu, Y.-H. Lin, W.-C. Su, S.-Y. Lin, K.-T. Chen, Y.-D. Li, W.-C. Chang, Y.-Z. Li, T.-H. Su, Y.-H. Liu, S.-W. Liu, Cathodic-controlled and near-infrared organic upconverter for local blood vessels mapping, Sci. Rep. 6 (2016) 32324. 
[18] S.-W. Liu, C.-C. Lee, C.-H. Yuan, W.-C. Su, S.-Y. Lin, W.-C. Chang, B.-Y. Huang, C.-F. Lin, Y.-Z. Lee, T.-H. Su, K.-T. Chen, Transparent organic upconversion devices for nearinfrared sensing, Adv. Mater. 27 (2015) 1217-1222.

[19] S.-W. Liu, Y.-Z. Li, S.-Y. Lin, Y.-H. Li, C.-C. Lee, Inducing the trap-site in an emittinglayer for an organic upconversion device exhibiting high current-gain ratio and low turn-on voltage, Org. Electronics 30 (2016) 275-280.

[20] M. Young, J. Suddard-Bangsund, T.J. Patrick, N. Pajares, C.J. Traverse, M.C. Barr, S.Y. Lunt, R.R. Lunt, Organic heptamethine salts for photovoltaics and detectors with near-infrared photoresponse up to 1600 nm, Adv. Opt. Mater. 4 (2016) 1028-1033.

[21] X. Gong, M. Tong, Y. Xia, W. Cai, J.S. Moon, Y. Cao, G. Yu, C.-L. Shieh, B. Nilsson, A.J. Heeger, High-detectivity polymer photodetectors with spectral response from 300 $\mathrm{nm}$ to $1450 \mathrm{~nm}$, Science 325 (2009) 1665-1667.

[22] J. Qi, J. Han, X. Zhou, D. Yang, J. Zhang, W. Qiao, D. Ma, Z.Y. Wang, Optimization of broad-response and high-detectivity polymer photodetectors by bandgap engineering of weak donor-strong acceptor polymers, Macromol. 48 (2015) 3941-3948.

[23] K. Strassel, A. Kaiser, S. Jenatsch, A.C. Véron, S.B. Anantharaman, E. Hack, M. Diethelm, F. Nüesch, R. Aderne, C. Legnani, S. Yakunin, M. Cremona, R. Hany, Squaraine dye for a visibly transparent all-organic optical upconversion device with sensitivity at 1000 nm, ACS Appl. Mater. Interfaces 10 (2018) 11063-11069.

[24] T.H. James, in: The Theory of the Photographic Process, $4^{\text {th }}$ ed., Macmillan, New York 1977.

[25] S. Jenatsch, L. Wang, N. Leclaire, E. Hack, R. Steim, S.B. Anantharaman, J. Heier, B. Ruhstaller, L. Penninck, F. Nüesch, R. Hany, Visible light-emitting host-guest electrochemical cells using cyanine dyes, Org. Electronics 48 (2017) 77-84. 
[26] A.C. Véron, H. Zhang, A. Linden, F. Nüesch, J. Heier, R. Hany, T. Geiger, NIR-absorbing heptamethine dyes with tailor-made counterions for application in light to energy conversion, Org. Lett. 16 (2014) 1044-1047.

[27] H. Zhang, G. Wicht, C. Gretener, M. Nagel, F. Nüesch, Y. Romanyuk, J.-N. Tisserant, R. Hany, Semitransparent organic photovoltaics using a near-infrared absorbing cyanine dye, Solar Energy Mater. Solar Cells 118 (2013) 157-164.

[28] C.J. Traverse, P. Chen, R.R. Lunt, Lifetime of organic salt photovoltaics, Adv. Energy Mater. (2018) 1703678.

[29] M. Makha, P. Schwaller, K. Strassel, S.B. Anantharaman, F. Nüesch, R. Hany, J. Heier, Insights into photovoltaic properties of ternary organic solar cells from phase diagrams, Sci. Techn. Adv. Mater. 19 (2018) 669-682.

[30] M. Bates, R.R. Lunt, Organic salt photovoltaics, Sustainable Energy Fuels 1 (2017) 955-968.

[31] B. Fan, F.A. de Castro, J. Heier, R. Hany, F. Nüesch, High performing doped cyanine bilayer solar cells, Org. Electronics 11 (2010) 583-588.

[32] C.J. Traverse, M. Young, J. Suddard-Bangsund, T. Patrick, M. Bates, P. Chen, B. Wingate, S.Y. Lunt, A. Anctil, R.R. Lunt, Anions for near-infrared selective organic salt photovoltaics, Sci. Rep. 7 (2017) 16399.

[33] H. Zhang, S. Jenatsch, J. De Jonghe, F. Nüesch, R. Steim, A.C. Véron, R. Hany, Transparent organic photodetector using a near-infrared absorbing cyanine dye, Sci. Rep. 5 (2015) 9439.

[34] R. Steim, F.R. Kogler, C.J. Brabec, Interface materials for organic solar cells, J. Mater. Chem. 20 (2010) 2499-2512. 
[35] J. Zou, K. Zhang, J. Li, Y. Zhao, Y. Wang, S.K.R. Pillai, H.V. Demir, X. Sun, M.B. ChanPark, Q. Zhang, Carbon nanotube driver circuit for $6 \times 6$ organic light emitting diode display, Sci. Rep. 5 (2015) 11755.

[36] L.S. Hung, C.W. Tang, M.G. Mason, Enhanced electron injection in organic electroluminescence devices using an Al/LiF electrode, Appl. Phys. Lett. 70 (1997) 152-154.

[37] W. Tress, A. Petrich, M. Hummert, M. Hein, K. Leo, M. Riede, Imbalanced mobilities causing S-shaped IV curves in planar heterojunction organic solar cells, Appl. Phys. Lett. 98 (2011) 063301.

[38] L. Wang, C. Hinderling, S. Jenatsch, F. Nüesch, D. Rentsch, R. Steim, H. Zhang, R. Hany, Cyanine dye polyelectrolytes for organic bilayer solar cells, Polymer 55 (2014) 31953201.

[39] S. Jenatsch, R. Hany, A.C. Véron, M. Neukom, S. Züfle, A. Borgschulte, B. Ruhstaller, F. Nüesch, Influence of molybdenum oxide interface solvent sensitivity on charge trapping in bilayer cyanine solar cells, J. Phys. Chem. C 118 (2014) 17036-17045.

[40] T.P. Osedach, A. lacchetti, R.R. Lunt, T.L. Andrew, P.R. Brown, G.M. Akselrod, V. Bulović, Near-infrared photodetector consisting of J-aggregating cyanine dye and metal oxide films, Appl. Phys. Lett. 101 (2012) 113303. 